\title{
Spent Coffee Grounds as Eco-Friendly Additives for Aluminum-Air Batteries
}

\author{
Woo-hyuk Lee, Seok-Ryul Choi, and Jung-Gu Kim*
}

Cite This: ACS Omega 2021, 6, 25529-25538

Read Online

ABSTRACT: A new approach to the recycling of spent coffee grounds is described in which lignin, a chemical component of spent coffee, is used as an electrolyte additive in aluminum-air batteries. The effect of lignin on the performance of aluminum-air batteries has been investigated by weight loss measurement, galvanostatic discharge test, and electrochemical impedance spectroscopy (EIS). The corrosion inhibition efficiency is improved up to $37.3 \%$ and fuel efficiency up to $21.7 \%$ at $500 \mathrm{ppm}$ of lignin molecules. The chemisorption of lignin molecules on the aluminum surface improves battery performance. Adsorption of lignin molecules onto the aluminum surface is driven by the electrostatic interaction between the lignin's hydroxyl group and the aluminum surface. The mechanism for the performance

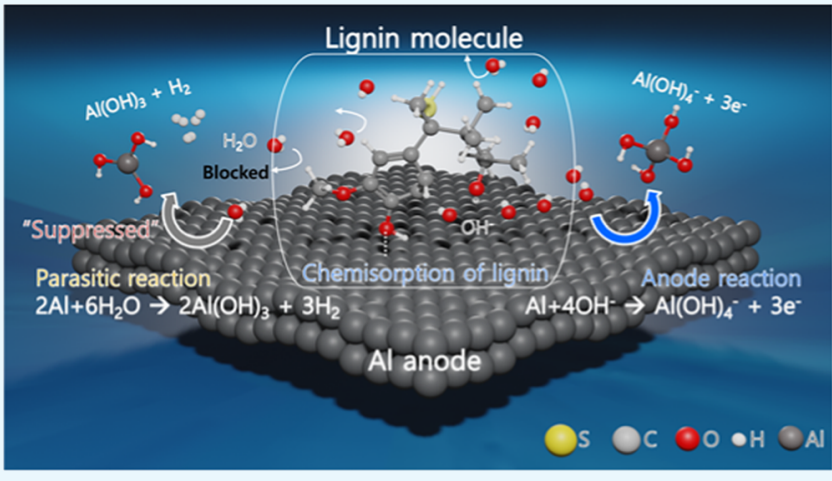
improvement is explained by the chemisorption behavior of lignin molecules. The adsorption behavior has been investigated by scanning electronic microscopy with energy-dispersive spectroscopy (SEM-EDS), laser scanning microscopy (LSM), atomic force microscopy (AFM), Freundlich adsorption isotherm, Fourier-transform infrared (FT-IR) spectroscopy, and the computational calculation of adsorption energies based on the density functional theory (DFT).

\section{INTRODUCTION}

The rapid depletion of fossil-fuel resources and growing environmental concerns have made clean-energy alternatives essential societal goals. Aluminum batteries are thought to be a viable energy storage system owing to the natural abundance of aluminum, the high charge storage capacity $\left(2980 \mathrm{mAh} \mathrm{g}^{-1}\right)$, and the low redox potential. Therefore, extensive research efforts have been focused on aluminum-based electrochemical storage technology. ${ }^{1}$ Aluminum batteries can be classified as aqueous and nonaqueous systems. Recent research on aqueous systems such as $\mathrm{Al}$-air batteries and $\mathrm{Al}$-ion batteries has been investigated to overcome their narrow electrochemical stability and low cell energy density due to $\mathrm{H}_{2} \mathrm{O}$ decomposition. ${ }^{2-4} \mathrm{On}$ the other hand, the nonaqueous systems including $\mathrm{Al}-$ ion, $\mathrm{Al}-$ sulfur, $\mathrm{Al}$-organic dual ion have focused on $\mathrm{Al}$ electrolyte chemistry such as chloroaluminate melts, deep eutectic solvents (DES), polymers, and chlorine-free formulations. ${ }^{5-7}$

Aluminum-air batteries in particular have shown promise because of their high theoretical voltage of $2.7 \mathrm{~V}$, recyclability, and low cost. ${ }^{8}$ However, aluminum-air batteries are vulnerable to parasitic self-corrosion in the form of the evolution of hydrogen gas. This hydrogen evolution reaction (HER) is more severe in alkaline electrolyte solutions. ${ }^{9}$ A hydrogen evolution reaction (HER) can lead to coulombic loss on discharge when hydrogen gas covers the surface of an aluminum anode. ${ }^{10}$ To address this drawback, various approaches have been proposed, including alloying ano- des, ${ }^{11-13}$ electrolyte additives, ${ }^{14-16}$ dual electrolytes, ${ }^{17}$ and oil displacement. ${ }^{4}$ Among the appropriate elements for the aluminum electrodes, ${ }^{18-20}$ indium, tin, zinc, magnesium, and gallium have been investigated. Indium (In) can shift the anode potential in a positive direction and enhance the overpotential of the HER. Tin ( $\mathrm{Sn})$ is associated with increasing the rates of $\mathrm{Al}$ dissolution in aqueous solutions and decreasing corrosion rates. ${ }^{18} \mathrm{Zinc}(\mathrm{Zn})$ has been shown to suppress the HER by enhancing the overpotential of the HER $^{19}$ Additionally, magnesium $(\mathrm{Mg})$ can improve the discharge performance of aluminum anodes by affecting the distribution of corrosion and grain size. ${ }^{20}$ An alternative approach is to use various electrolyte additives to control parasitic corrosion reactions. Recent research has focused on developing nontoxic and cost-effective additives. Organic additives are more promising candidates for a low-cost and environmentally friendly inhibitor compared with inorganic additives. $^{21,22}$ Nonoxylnol-9 suppresses the corrosion of $\mathrm{Al}$ anodes in an alkaline solution, and the improved battery

Received: July 6, 2021

Accepted: September 9, 2021

Published: September 27, 2021 
performance has been reported due to the adsorption of organic molecules on the Al surface. ${ }^{21}$ Additionally, urea and thiourea molecules show a positive effect on inhibiting corrosion reaction of anodes in aluminum-air batteries due to their adsorption on the anode surface. ${ }^{22}$

Considerable efforts are being made to utilize spent coffee grounds as a renewable, environmentally friendly, and costeffective resource in a variety of industrial fields, including textiles, biopolymers, biofuels, food, and pharmaceuticals. ${ }^{23}$ Spent coffee grounds are composed of organic composites, including lignin and polysaccharides. Lignin is the second-most abundant biopolymer on earth. ${ }^{24}$ Lignin is a three-dimensional biopolymer with a complex and nonuniform structure with aliphatic and aromatic constituents including hydroxyl, carboxyl, benzyl alcohol, methoxy, and aldehyde functional groups (Figure S1). Lignin also has a relatively large surface area of $180 \mathrm{~m}^{2} \mathrm{~g}^{-1}$, which makes it suitable as an organic inhibitor that prevents the self-corrosion reaction in aluminum-air cell systems when combined with the properties of its functional groups. Recently, various studies have revealed that lignin can be used as the electrode component in the energy storage system including lead-acid batteries, lithium-ion batteries, solar cells, and fuel cells. ${ }^{25}$ On the other hand, the extraction of alkaline lignin from organic materials has been well studied. ${ }^{26}$ Furthermore, the previous research work has published the result of the successful extraction of lignin from coffee husks using an ionic liquid. ${ }^{27}$ They used ammoniumbased ionic liquid not only for dissolving the coffee husk but also for extracting and depredating the lignin content under mild conditions. The highest yield has been achieved with $71.2 \%$ when the coffee husk has been treated with [DIPEA][Ac] at $120{ }^{\circ} \mathrm{C}$ for $4 \mathrm{~h}$. As the technology for extracting lignin from coffee grounds is advancing, it is worth examining the feasibility of lignin in an aluminum-air battery.

Here, we describe for the first time the use of lignin as an electrolyte additive in an aluminum-air battery. The main objective is to improve the battery performance and suppress self-corrosion reactions by investigating the behavior of lignin molecules in an aluminum battery system with a pure aluminum electrode (99.99\%) in a $4 \mathrm{M} \mathrm{NaOH}$ electrolyte. The investigation has been conducted using both experimental electrochemical analysis and quantum chemical calculations. In the electrochemical analysis, the corrosion behavior and properties of lignin in the system were examined in detail by weight-loss analysis, discharge and polarization tests, and electrochemical impedance spectroscopy (EIS). Surface morphologies were examined by scanning electron microscopy (SEM), laser scanning microscopy (LSM), atomic force microscopy (AFM), and Fourier-transform infrared (FT-IR) spectroscopy. In quantum chemical calculations, Materials Studio software (BIOVIA) is used to simulate the inhibition mechanism based on an inhibition isotherm, charge distribution analysis, and ab initio molecular dynamics (AIMD) simulation.

\section{RESULTS AND DISCUSSION}

Effect of Lignin on the Electrochemical Behavior of an Aluminum Anode. Measurements of weight loss, $\Delta W$ $\left(\mathrm{mg} \mathrm{cm}{ }^{-2}\right)$, and inhibition efficiency, $\eta_{\mathrm{W}}(\%)$, are shown in Table 1. The inhibition efficiencies $\left(\eta_{\mathrm{w}}\right)$ are calculated according to the following equation

$$
\eta_{\mathrm{W}}=\left[\left(W_{0}-W_{\mathrm{c}}\right) / W_{0}\right] \times 100
$$

Table 1. Parameters of Weight Loss after $1 \mathrm{~h}$ of Immersion at Different Concentrations of Lignin Molecules

\begin{tabular}{ccc} 
additive $(\mathrm{ppm})$ & weight loss, $\Delta W\left(\mathrm{mg} \mathrm{cm}^{-2}\right)$ & inhibition efficiency, $\eta_{\mathrm{W}}(\%)$ \\
0 & 16.9 & \\
100 & 13.7 & 18.9 \\
300 & 11.5 & 32.0 \\
500 & 10.6 & 37.3 \\
600 & 8 & 52.7 \\
700 & 7.8 & 54.1 \\
800 & 7.6 & 55.3 \\
1000 & 6.6 & 61.2 \\
1500 & 4.5 & 73.4 \\
\hline
\end{tabular}

where $W_{0}$ and $W_{\mathrm{c}}$ are the average weight loss without and with the addition of lignin molecules, respectively. The largest weight loss in the unit area after $1 \mathrm{~h}$ is $16.9 \mathrm{mg} \mathrm{cm}^{-2}$ in the absence of lignin molecules in the electrolyte. The smallest amount is $4.5 \mathrm{mg} \mathrm{cm}^{-2}$ in the presence of $1500 \mathrm{ppm}$ lignin, which represents an inhibition efficiency of $73.4 \%$ compared with that of the blank condition. The weight losses gradually decrease as the concentration of lignin molecules increases from 0 to $1500 \mathrm{ppm}$. Inhibition efficiencies increase with the number of lignin molecules in the electrolyte. These results indicate that the parasitic corrosion reaction is suppressed by lignin molecules.

To figure out the relationship between the battery performance and the inhibition of parasitic corrosion reaction by lignin molecules, the galvanostatic discharge test for $4 \mathrm{~N}$ aluminum in $4 \mathrm{M} \mathrm{NaOH}$ containing lignin molecules is conducted and the results are shown in Figure 1 and Table 2.

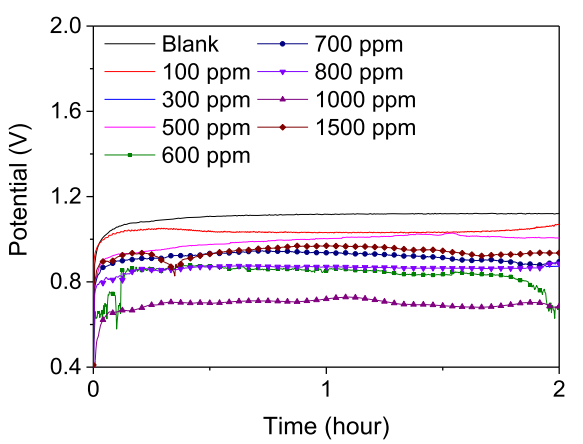

Figure 1. Galvanostatic discharge test at $20 \mathrm{~mA} \mathrm{~cm}^{-2}$ for $2 \mathrm{~h}$ in the presence and absence of lignin molecules in $4 \mathrm{M} \mathrm{NaOH}$.

The cell potentials in the presence of an additive decrease to $0.70 \mathrm{~V}$ compared to $1.12 \mathrm{~V}$ in the absence of an additive. The weight loss in the presence of lignin molecules decreases to $0.0115 \mathrm{~g} \mathrm{~cm}^{-2}$ compared with $0.0362 \mathrm{~g} \mathrm{~cm}^{-2}$ in the absence of lignin molecules. The capacity density (in $\mathrm{Ah} \mathrm{cm}^{-2}$ ), energy density (in $\mathrm{Wh} \mathrm{kg}^{-1}$ ), and fuel efficiency (in \%) are calculated using the following formulas

$$
\begin{aligned}
& \text { capacity density }=I h / \Delta m \\
& \text { energy density }=(V \cdot I h) / \Delta m \\
& \text { fuel efficiency }=(\text { specific energy density }) \\
& /(\text { theoretical energy density })
\end{aligned}
$$

where $I$ is the current (in A), $h$ is the time (in h), $\Delta m$ is the weight loss (in $\mathrm{g}$ ), $V$ is the average voltage (in V), and 8100 
Table 2. Parameters of Galvanostatic Discharge at $20 \mathrm{~mA} \mathrm{~cm}$ for $2 \mathrm{~h}$ Based on Weight Loss Measurements of Aluminum in the Presence and Absence of Lignin Molecules in $4 \mathrm{M} \mathrm{NaOH}$ Solution

\begin{tabular}{|c|c|c|c|c|c|c|}
\hline $\begin{array}{l}\text { concentration } \\
(\mathrm{ppm})\end{array}$ & $\begin{array}{l}\text { weight loss } \\
\left(\mathrm{g} \mathrm{cm}^{-2}\right)\end{array}$ & $\begin{array}{l}\text { average voltage } \\
\text { (V) }\end{array}$ & $\begin{array}{l}\text { capacity density } \\
\left(\mathrm{mAh} \mathrm{g}^{-1}\right)\end{array}$ & $\begin{array}{l}\text { current efficiency } \\
(\%)\end{array}$ & $\begin{array}{l}\text { energy density } \\
\left(\mathrm{Wh} \mathrm{kg}^{-1}\right)\end{array}$ & $\begin{array}{l}\text { fuel efficiency } \\
(\%)\end{array}$ \\
\hline 0 & 0.0362 & 1.12 & 553.25 & 18.57 & 619.64 & 7.65 \\
\hline 100 & 0.0222 & 1.04 & 902.93 & 30.30 & 935.44 & 11.55 \\
\hline 300 & 0.0172 & 0.81 & 1162.79 & 39.02 & 946.51 & 11.69 \\
\hline 500 & 0.0115 & 0.99 & 1746.72 & 58.61 & 1729.26 & 21.35 \\
\hline 600 & 0.0140 & 0.83 & 1433.69 & 48.11 & 1194.27 & 14.74 \\
\hline 700 & 0.0144 & 0.92 & 1393.73 & 46.77 & 1276.66 & 15.76 \\
\hline 800 & 0.0134 & 0.86 & 1498.13 & 50.27 & 1292.88 & 15.96 \\
\hline 1000 & 0.0390 & 0.70 & 512.82 & 17.21 & 356.92 & 4.41 \\
\hline 1500 & 0.0377 & 0.94 & 530.50 & 17.80 & 498.14 & 6.15 \\
\hline
\end{tabular}

Wh $\mathrm{kg}^{-1}$ of the theoretical gravimetric energy density is used in the calculation. The greatest inhibition efficiency, $21.35 \%$, is obtained with $500 \mathrm{ppm}$ of lignin molecules in the electrolyte compared with $7.65 \%$ for the blank condition. The inhibition efficiency increases gradually to a critical concentration point at $500 \mathrm{ppm}$, but then gradually decreases as the concentration increases from 600 to $1500 \mathrm{ppm}$. This result conflicts with those of the weight-loss measurements. The reason for this phenomenon is covered by the following electrochemical analysis. The calculated parameters indicate that the addition of lignin molecules to $4 \mathrm{M} \mathrm{NaOH}$ at specific concentrations improves the discharge performance of aluminum-air batteries. Moreover, the result as shown in Table 1 represents the shelf-life and the stability of the battery system. The amount of weight loss represents $\mathrm{Al}$ electrode consumption per hour in the presence and absence of lignin molecules in the battery system because all of the $\mathrm{Al}$ electrodes have the same thickness, exposure area, and exposure time. By comparing the amount of weight loss at $500 \mathrm{ppm}$ to that of $0 \mathrm{ppm}$, the shelflife of the battery at $500 \mathrm{ppm}\left(\Delta W=8 \mathrm{mg} \mathrm{cm}^{-2}\right)$ is approximately twice longer than that of $0 \mathrm{ppm}(\Delta W=16.9 \mathrm{mg}$ $\mathrm{cm}^{-2}$ ). Therefore, it is manifested that the battery system with lignin as an additive has a longer shelf-life and excellent stability.

To examine the interactions between lignin molecules and the $\mathrm{Al}$ surface, potentiodynamic polarization tests are performed on the $\mathrm{Al}$ anode at different concentrations of lignin molecules. Figure 2 depicts the polarization curves for different concentrations of lignin molecules at room temperature. The polarization parameters including corrosion potential $\left(E_{\text {corr }}\right)$, anodic Tafel constant $\left(\beta_{\mathrm{a}}\right)$, cathodic Tafel constant $\left(\beta_{\mathrm{c}}\right)$, corrosion current density $\left(i_{\text {corr }}\right)$, and corrosion inhibition efficiency $\left(\eta_{\mathrm{e}}\right)$, are shown in Table 3. Corrosion

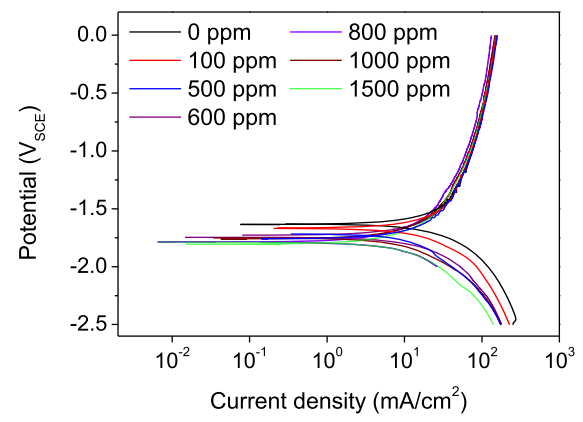

Figure 2. Potentiodynamic polarization curves in the presence and absence of lignin molecules in $4 \mathrm{M} \mathrm{NaOH}$.
Table 3. Tafel Polarization Parameters and Corrosion Inhibition Efficiencies for Aluminum in a $4 \mathrm{M} \mathrm{NaOH}$ Solution in the Presence and Absence of Lignin Molecules

\begin{tabular}{|c|c|c|c|c|c|}
\hline $\begin{array}{l}\text { concentration } \\
(\mathrm{ppm})\end{array}$ & $\begin{array}{l}-E_{\text {corr }} \\
\text { (V) }\end{array}$ & $\begin{array}{c}\beta_{\mathrm{a}} \\
\left(\mathrm{mV} \mathrm{\operatorname {dec } ^ { - 1 }}\right)\end{array}$ & $\begin{array}{c}-\beta_{\mathrm{c}} \\
\left(-\mathrm{mV} \operatorname{dec}^{-1}\right)\end{array}$ & $\left(\mathrm{mA} \mathrm{cm}^{i_{\text {corr }}}{ }^{-2}\right)$ & $\begin{array}{c}\eta_{\mathrm{e}} \\
(\%)\end{array}$ \\
\hline 0 & 1.63 & 1.670 & 0.854 & 41.52 & \\
\hline 100 & 1.67 & 2.666 & 0.967 & 37.53 & 9.6 \\
\hline 500 & 1.74 & 2.425 & 1.003 & 33.92 & 18.3 \\
\hline 600 & 1.74 & 2.063 & 0.930 & 31.89 & 23.2 \\
\hline 800 & 1.78 & 2.020 & 0.864 & 27.48 & 33.8 \\
\hline 1000 & 1.76 & 1.690 & 0.828 & 25.84 & 37.8 \\
\hline 1500 & 1.80 & 1.431 & 0.775 & 21.17 & 49.0 \\
\hline
\end{tabular}

inhibition efficiencies $\left(\eta_{\mathrm{e}}\right)$ are calculated according to the following equation

$$
\eta_{\mathrm{e}}=\left[\left(I_{\text {corr }_{0}}-I_{\text {corr }_{\mathrm{c}}}\right) / I_{\text {corr }_{0}}\right] \times 100
$$

where $I_{\text {corrc }_{c}}$ and $I_{\text {corr }_{0}}$ are the corrosion rates in the presence and absence of lignin molecules, respectively. As shown in Table 3, the aluminum anode achieves the lowest corrosion resistance in $4 \mathrm{M} \mathrm{NaOH}$ in the absence of lignin molecules, as indicated by a large $i_{\text {corr }}\left(41.52 \mathrm{~mA} \mathrm{~cm}{ }^{-2}\right)$. The $i_{\text {corr }}$ decreases as the concentration of lignin molecules increases, leading to an improvement in $\eta_{\mathrm{e}}$. This result is related to the increase in the number of adsorbed molecules on the $\mathrm{Al}$ surface. The adsorption behavior can be explained by the creation of a complex film (between the aluminum surface and lignin molecules) driven by the adsorption activity of sulfide and hydroxyl groups in one of the lignin isomers. ${ }^{28,29}$ In addition, adsorption of sulfide and hydroxyl groups must compete with adsorption of $\mathrm{OH}^{-}$ions and water molecules on the $\mathrm{Al}$ surface. In organic inhibitor systems, the lone-pair electrons of oxygen and sulfur atoms can provide enough electrons to interact with the empty $3 \mathrm{p}$ orbital of surface $\mathrm{Al}$ atoms, and chemisorption between the $\mathrm{Al}$ surface and lignin molecules can occur. ${ }^{15}$ The competitive adsorption of lignin molecules reduces the reactive surface area while maintaining the anodic dissolution rate, possibly due to the complex film on the $\mathrm{Al}$ surface, which can block water molecules from the $\mathrm{Al}$ surface and suppress the parasitic corrosion reaction, while $\mathrm{OH}^{-}$ions can reach the $\mathrm{Al}$ surface though the complex film in an aluminum dissolution reaction.

The addition of lignin molecules has a significant inhibiting effect on the cathodic reaction, shifting $E_{\text {corr }}$ values toward negative values. Also, cathodic polarization curves are due to the addition of lignin molecules, while anodic polarization curves remain similar to those for the absence of lignin 

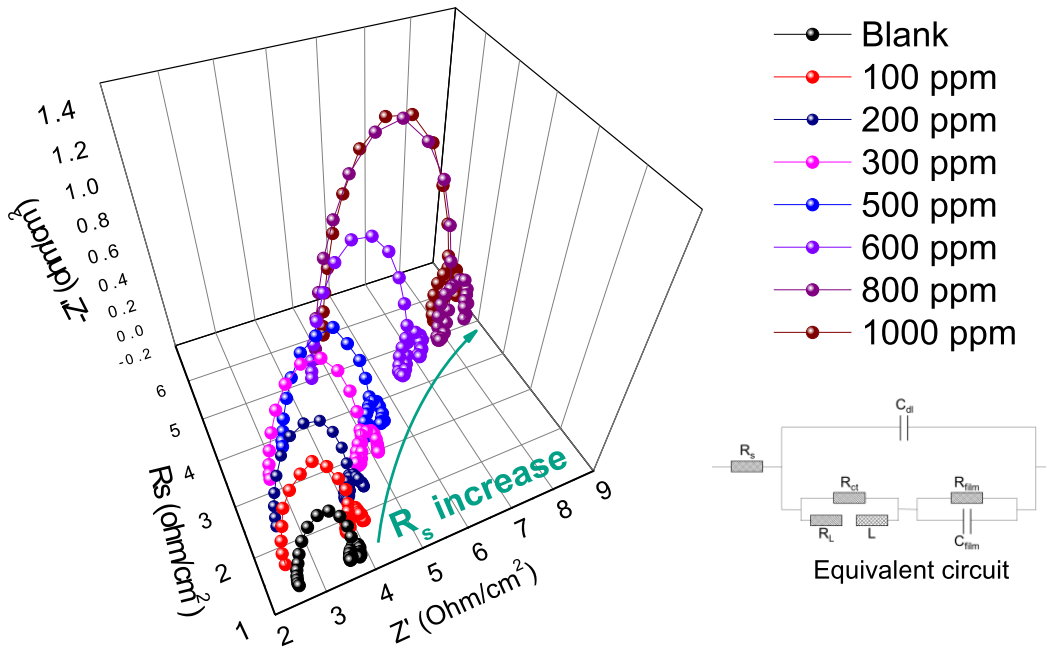

Equivalent circuit

Figure 3. Nyquist plots of the $\mathrm{Al}$ anode in the presence and absence of lignin molecules in $4 \mathrm{M} \mathrm{NaOH}$.

Table 4. Electrochemical Parameters of the Al Anode in the Presence and Absence of Lignin Molecules in $4 \mathrm{M} \mathrm{NaOH}$ Solution

$\begin{array}{rcccccccc}\text { concentration }(\mathrm{ppm}) & R_{\mathrm{s}}\left(\Omega \mathrm{cm}^{2}\right) & \mathrm{CPE}_{1} Y_{0}\left(\mu \mathrm{F} \mathrm{cm}^{-2}\right) & \text { frequency power } & R_{\mathrm{ct} 1}\left(\Omega \mathrm{cm}^{2}\right) & R_{\mathrm{L} 1}\left(\Omega \mathrm{cm}^{2}\right) & L_{1}\left(\mathrm{H} \mathrm{cm}^{2}\right) & C_{\text {film }}\left(\mathrm{F} \mathrm{cm}^{2}\right) & R_{\text {film }}\left(\Omega \mathrm{cm}^{2}\right) \\ 0 & 2.505 & 7.127 \times 10^{-5} & 0.9819 & 0.943 & 0.1293 & 0.0001748 & 0.06563 \\ 100 & 2.458 & 1.787 \times 10^{-5} & 1 & 1.174 & 0.1332 & 0.0001444 & 0.06721 & 0.2529 \\ 200 & 2.532 & 2.213 \times 10^{-5} & 0.9776 & 1.347 & 0.1483 & 0.0001669 & 0.08075 & 0.3897 \\ 300 & 2.63 & 3.112 \times 10^{-5} & 0.9281 & 1.749 & 0.2065 & 0.0002155 & 0.06735 & 0.4994 \\ 400 & 2.638 & 2.448 \times 10^{-5} & 0.9443 & 1.953 & 0.2228 & 0.000321 & 0.06147 & 0.6019 \\ 500 & 2.563 & 1.82 \times 10^{-5} & 0.9727 & 1.947 & 0.2091 & 0.0003672 & 0.06384 & 0.5686 \\ 600 & 4.15 & 2.72 \times 10^{-5} & 0.9254 & 2.013 & 0.2912 & 0.0004678 & 0.05518 & 0.5686 \\ 800 & 4.472 & 3.367 \times 10^{-5} & 0.9104 & 2.954 & 0.4026 & 0.0007165 & 0.07254 & 0.7679 \\ 1000 & 4.901 & 2.714 \times 10^{-5} & 0.9279 & 2.736 & 0.4183 & 0.0006761 & 0.07334 & 0.7118 \\ & & & & & & \end{array}$

molecules. This indicates that the addition of lignin molecules to the electrolyte suppresses the cathodic reaction while the anodic dissolution process has no effect. Lignin can therefore be classified as a cathodic inhibitor. ${ }^{28}$ This is consistent with the weight-loss measurements.

The nearly parallel polarization curves indicate that the presence of lignin molecules does not alter the mechanism of the HER. Instead, the reaction is retarded by the adsorption of lignin molecules on the $\mathrm{Al}$ surface, which is attributed to the decrease of the surface area for the HER. ${ }^{30,31}$

Electrochemical impedance plots of the $\mathrm{Al}$ electrode in $4 \mathrm{M}$ $\mathrm{NaOH}$ in the presence and absence of lignin molecules are shown in Figure 3. The impedance is measured at the opencircuit potential (OCP) from 0 to $1500 \mathrm{ppm}$ of lignin molecules. Each impedance spectrum is composed of three loops. The first capacitive loop at high frequencies is related to the charge-transfer resistance, which is attributed to the redox $\mathrm{Al}-\mathrm{Al}^{+}$reaction. The inductive loop at middle frequencies is due to the adsorption of the intermediates including $\mathrm{Al}(\mathrm{OH})_{\text {ads }}, \mathrm{Al}(\mathrm{OH})_{2, \mathrm{ads}}, \mathrm{Al}(\mathrm{OH})_{3, \mathrm{ads}}$, and $\mathrm{Al}(\mathrm{OH})_{4 \mathrm{ads}}{ }^{-}$. The second capacitive loop at low frequencies is related to the complementary redox reaction of $\mathrm{Al}^{+}-\mathrm{Al}^{3+} \cdot{ }^{26,3226,32}$

An equivalent circuit shown as an inset plot in Figure 3 verifies the impedance spectra in the presence and absence of lignin molecules. The equivalent circuit is composed of the solution resistance $\left(R_{s}\right)$, the constant phase elements (CPEs) $\left(C_{\mathrm{d}}, C_{\text {film }}\right)$, the capacitance resistances $\left(R_{\mathrm{ct}}, R_{\mathrm{film}}\right)$, the inductance resistance $\left(R_{\mathrm{L}}\right)$, and the inductance $(L)$. The impedance $\left(Z_{\mathrm{CPE}}\right)$ can be derived from the following equation

$$
Z_{\mathrm{CPE}}=Y_{0}^{-1}(\mathrm{j} w)^{-n}
$$

where $Y_{0}$ is the magnitude of CPEs, $\mathrm{j}$ is the imaginary root, $w$ is the angular frequency (in $\mathrm{rad} \mathrm{s} \mathrm{s}^{-1}$ ), and $n$ is the exponential term ranging between 0 and 1 . The fitting values of different resistances in the equivalent circuits are listed in Table 4. Within a 5\% error margin, the fitting results are consistent with the experimental result. The presence of an inductive element indicates that the corrosion reaction is induced by direct charge transfer at the adsorbed inhibitor on the $\mathrm{Al}$ surface. ${ }^{33} \mathrm{In}$ addition, the inductance values increase as the concentration of lignin molecules increases, as shown in Table 4. This increase in inductance indicates the changes in the relaxation time according to the following equation

$$
H=R \tau
$$

where $\tau$ is the relaxation time for adsorption on the $\mathrm{Al}$ surface and $R$ is the polarization resistance from the DC limit for the impedance. ${ }^{14}$ In the presence of lignin molecules, an increase in $R_{\mathrm{ct}}$ results in a decrease in $C_{\mathrm{dl}}$. An increase in $\tau$ can therefore explain the increase in $L$. The adsorption of lignin molecules on the $\mathrm{Al}$ surface, which replaces water molecules at the anode/electrolyte interfaces, results in a reduction in $C_{\mathrm{dl}}$ and an increase in $L .^{34}$ This relationship between $C_{\mathrm{dl}}$ and $L$ is a product of the decrease in active sites on the $\mathrm{Al}$ surface, which is responsible for the corrosion reaction and leads to an increase in inhibition efficiency. This is consistent with weightloss measurements and the results of potentiodynamic tests, as shown in Tables 1 and 3.

As the concentration of lignin molecules increases, the parameters, including $R_{\mathrm{s}}, R_{\mathrm{ct}}$, and $R_{\mathrm{s}}+R_{\mathrm{ct}}$ (related to the improvement of corrosion resistance) also increase, as shown in Table 4. The largest $R_{\mathrm{s}}$ and $R_{\mathrm{ct}}$ values are measured in the 
presence of lignin molecules at $1000 \mathrm{ppm}$, indicating superior corrosion resistance compared with other concentrations. However, $1000 \mathrm{ppm}$ is not an ideal concentration in terms of battery discharge efficiency. As shown in Table 3, the highest discharge efficiency is obtained at $500 \mathrm{ppm}$, and efficiency decreased at higher concentrations. This indicates that an ideal surface coverage by lignin molecules is achieved at $500 \mathrm{ppm}$, and the lack of participation of residual lignin molecules in surface adsorption contributes to the decrease in discharge efficiency at concentrations of $600-1000 \mathrm{ppm}$. The relationship between the degradation of discharge efficiency and residual lignin molecules can be explained by the rapid increase in $R_{\mathrm{s}}$ values. As illustrated in Figure 3, the curves for concentrations below $500 \mathrm{ppm}$ are not shifted due to similar $R_{\mathrm{s}}$ values of $2.485-2.63 \Omega \mathrm{cm}^{2}$. However, the curves for concentrations above $500 \mathrm{ppm}$ are shifted clearly to the right side due to $R_{\mathrm{s}}$ values of $4.15-4.901 \Omega \mathrm{cm}^{2}$. An increase of $R_{\mathrm{s}}$, therefore, causes a decrease in electrolyte conductivity. According to the discharge efficiency result, the residual additives can be attributed to reductions in the effect of the corrosion inhibition of the adsorbates while aluminum dissolution reaction is accelerated by an external power. The residual lignin causes a chain entanglement that stabilizes the three-dimensional network of the polymer containing the physical cross-linking of noncovalently bonded polymer chains. ${ }^{35,36}$ The effect of chain entanglement is responsible not only for the increased $R_{\mathrm{s}}$ but also the reduction of the corrosion inhibition effect due to physical/chemical forces, including electrostatic repulsion and van der Waals attractions induced by chain entanglement units. Consequently, the decrease in the discharge efficiency at a specific concentration is related to the chain entanglement of lignin molecules and is responsible for the reduction in the corrosion inhibition of lignin molecules.

Adsorption Behavior of Lignin in Al-Air Battery. Electrochemical analysis verifies that lignin molecules can inhibit the corrosion of $\mathrm{Al}$ anode and act as a cathodic inhibitor in $4 \mathrm{M} \mathrm{NaOH}$. To further understand the mechanism of the adsorption process of lignin molecules on $\mathrm{Al}$ surfaces, the Freundlich adsorption isotherm is used to investigate the mode of adsorption and the characteristics of lignin molecules. The linear form of the Freundlich isotherm is as follows ${ }^{37}$

$$
\log (\theta)=\log \left(K_{\mathrm{F}}\right)+1 / n \log C_{\mathrm{inh}}
$$

where $C_{\text {inh }}$ is the inhibitor concentration, and $K_{\mathrm{F}}$ and $n$ are Freundlich and empirical constants, respectively. The surface coverages by lignin molecules $(\theta)$ are calculated from the weight loss test and electrochemical data according to the following equation $^{38}$

$$
\theta=\text { (inhibition efficiency) } / 100
$$

Freundlich isotherm plots and estimated parameters for the adsorption of lignin molecules on the $\mathrm{Al}$ surface are shown in Figure 4 and Table 5. In Table 5, regression coefficient values $\left(R^{2}\right)$ characterize the degree of Freundlich adsorption in the system. The adsorption of lignin molecules on the $\mathrm{Al}$ surface is conformed to Freundlich-type adsorption behavior since $R^{2}$ values are closer to 1.0. The degree of stability of lignin molecules on the $\mathrm{Al}$ surface is shown with the slope $(1 / n)$ in a range of $0-1 . K_{\mathrm{F}}$ is Gibb's free energy of adsorption $\left(\Delta G_{\mathrm{ads}}{ }^{\circ}\right)$ with the following relationship ${ }^{30}$

$$
\Delta G_{\mathrm{ads}}^{\circ}=-R T \ln \left(55.5 K_{\mathrm{F}}\right)
$$

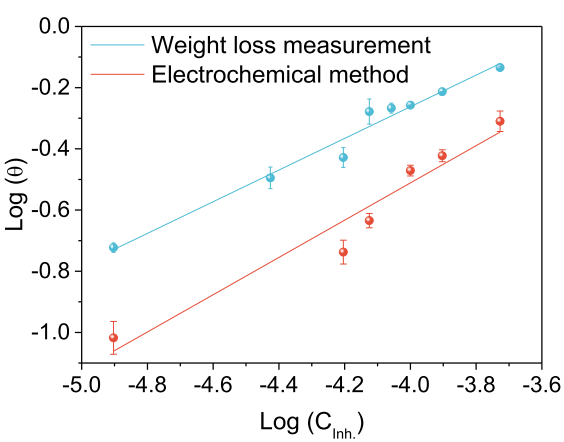

Figure 4. Freundlich adsorption plot for aluminum in a $4 \mathrm{M} \mathrm{NaOH}$ solution containing lignin molecules at $300 \mathrm{~K}$.

Table 5. Estimated Parameters from a Freundlich Isotherm for Adsorption of Lignin Molecules on an Aluminum Surface in $4 \mathrm{M} \mathrm{NaOH}$

\begin{tabular}{lcc}
\multicolumn{1}{c}{ parameters } & weight loss measurement & electrochemical method \\
$R^{2}$ & 0.967 & 0.930 \\
$K_{\mathrm{F}}\left(\mathrm{M}^{-1}\right)$ & 64.04 & 83.90 \\
$1 / n$ & 0.517 & 0.609 \\
$\Delta G_{\text {ads }}\left(\mathrm{kJ} \mathrm{mol}^{-1}\right)$ & -20.60 & -21.28 \\
\hline
\end{tabular}

where $R$ is the ideal gas constant $\left(8.314 \mathrm{~J} \mathrm{~K}^{-1} \mathrm{~mol}^{-1}\right)$ and $T$ is the thermodynamic temperature. The inhibitor molecules contribute to electrostatic interactions with the metal surface through physisorption at an absolute $\Delta G_{\text {ads }}{ }^{\circ}$ value $\geq 20 \mathrm{~kJ}$ $\mathrm{mol}^{-1}$. The inhibitor molecules transfer electrons to the metal surface through chemisorption at an absolute $\Delta G_{\text {ads }}{ }^{\circ}$ value of $\leq 40 \mathrm{~kJ} \mathrm{~mol}^{-1}$. ${ }^{38,3938,39}$ The calculated values of $\Delta G_{\mathrm{ads}}{ }^{\circ}$ are -20.6 and $-21.28 \mathrm{~kJ} \mathrm{~mol}^{-1}$, indicating that the adsorption of lignin molecules on the $\mathrm{Al}$ surface is driven by a physicochemisorption process.

Figure 5 shows the SEM-EDS data for the aluminum surface after $1 \mathrm{~h}$ of immersion in the presence and absence of lignin molecules. The difference in the morphologies of the aluminum surface with and without lignin molecules is shown in Figure 5a,b. In Figure 5b, only pores due to the aluminum dissolution process are observed. In contrast, the adhesion of adsorbate on the aluminum surface can be clearly observed in Figure 5a. The adsorbate appears to be aligned along the edge of pores on the aluminum surface. It is reasonable to assume that pore edges are favorable positions for adsorbates in the competitive adsorption process ${ }^{40}$ because of the high specific area of the edges compared with a flat surface. To verify whether the adsorbate is composed of lignin molecules, two different positions are selected according to the presence or absence of adsorbate, as shown in Figure 5c,d. The exact point of SEM analysis where the adsorbates are clearly observed is illustrated in Figure 5c, and the EDS result at the point is also shown in Figure 5e. In the same vein, the SEMEDS analysis at which no adsorbates are observed is shown in Figure 5d,f, respectively. The detection of $50.2 \mathrm{wt} \%$ carbon can be attributed to lignin molecules, as shown in Figure 5e. However, only 5.7 wt \% of carbon is detected, as illustrated in Figure 5f. A comparison of the EDS results in Figure 5e,f confirms that the adsorbed material is lignin molecules, which is consistent with the Freundlich isotherm and electrochemical analyses, as well as the potentiodynamic and EIS tests.

Further investigations have been conducted by laser scanning microscopy (LSM) and atomic force microscopy 

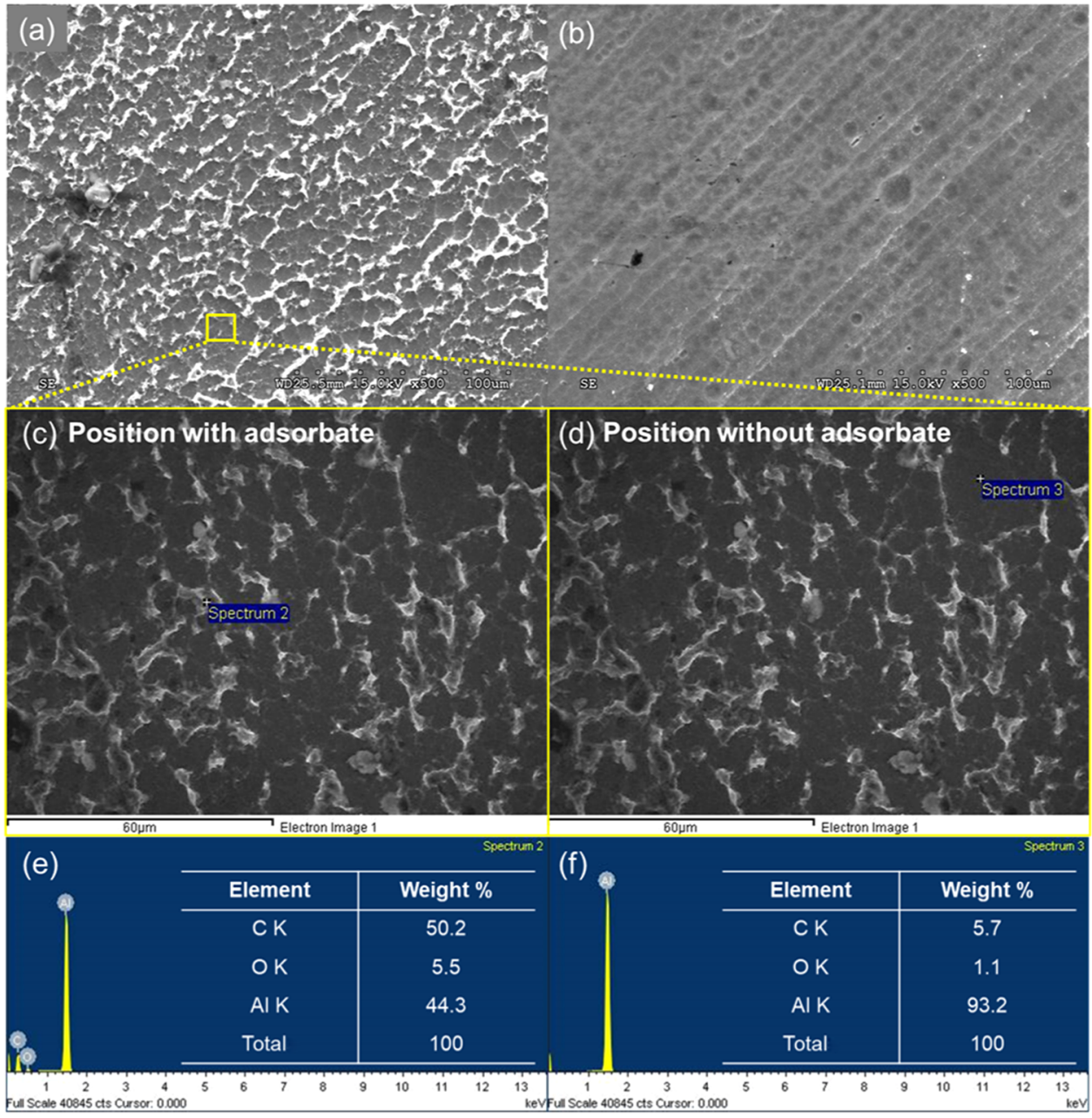

Figure 5. SEM micrographs of the aluminum surface after $1 \mathrm{~h}$ of immersion in the presence (a) and absence of lignin molecules (b). SEM micrographs showing different adsorption features $(c, d)$ and EDS analysis results of each position (e, f).

(AFM) to obtain better insight into the adsorption behavior of lignin molecules on the Al surface. Figure S2 illustrates the LSM micrographs of the Al surface after $1 \mathrm{~h}$ of immersion in the presence and absence of lignin molecules in the electrolyte. Figure S2a,c,e shows the Al surface without lignin molecules while Figure S2b,d,f represents the Al surface with lignin molecules. From the comparison of Figure S2c,d, it is obvious that the contrast difference between microstructure depends on the adsorption behavior of lignin molecules. Also, from the comparison of Figure S2e,f, the difference in maximum height due to the adsorption of lignin molecules can be clearly seen and the maximum height in Figure S2f is obtained as 0.308 $\mu \mathrm{m}$, while the maximum height in Figure S2e is obtained as $0.107 \mu \mathrm{m}$.

Although LSM is a powerful tool to investigate the microstructure of the $\mathrm{Al}$ surface, it is insufficient to derive topological information including chemical and mechanical properties depending on the adsorption behavior of lignin molecules. Therefore, AFM analysis has been examined and the topology of the $\mathrm{Al}$ surface in the presence and absence is illustrated in Figure S3. As it can be seen in Figure 5a, the topological feature having a cluster shape judged to be lignin molecules is obtained in Figure 3Sb,d, while the topology of clustered lignin molecules has not been identified in Figure S3a,c. Moreover, from the comparison of the height profile between Figure S3e and f, the maximum height in the presence of lignin molecules is obtained as $83.5 \mathrm{~nm}$ (Figure S3f), while the maximum height in the absence of lignin molecules is 34 $\mathrm{nm}$ (Figure S3e). It is manifested that the same topological feature due to the adsorption behavior of lignin molecules has been confirmed by SEM, LSM, and AFM analysis.

Fourier-transform infrared spectra analysis is performed to verify the changes in the molecular structure and chemical bonds due to the physicochemisorption process of lignin molecules on the aluminum surface. The adsorption structure can be explained by the infrared spectrum analysis, which also elucidates the type of bonding for adsorption on the metal surface. The reflected FT-IR spectra after $1 \mathrm{~h}$ of immersion in the presence and absence of lignin molecules are shown in Figure 6. The broad peak from 3400 to $3700 \mathrm{~cm}^{-1}$ represents $\mathrm{O}-\mathrm{H}$ stretching vibrations, the peak at $2917 \mathrm{~cm}^{-1}$ is related to $\mathrm{C}-\mathrm{O}-\mathrm{CH}_{3}$ stretching vibrations, the peak at $1577 \mathrm{~cm}^{-1}$ signifies the $\mathrm{C}=\mathrm{C}$ stretching vibration, the peak at 1473 $\mathrm{cm}^{-1}$ represents $\mathrm{C}-\mathrm{H}$ bending, and the peak at $663 \mathrm{~cm}^{-1}$ indicates the out-of-plane bending of phenols. ${ }^{41}$ The peak intensity of the $\mathrm{O}-\mathrm{H}$ stretching vibration decreases in the presence of lignin molecules compared with that in the absence of lignin molecules, while the high intensity of the $\mathrm{O}-\mathrm{H}$ stretching peak is observed in the lignin powder. In addition, the other peaks, such as those for the $\mathrm{C}-\mathrm{O}-\mathrm{CH}_{3}$ stretching vibration at $2917 \mathrm{~cm}^{-1}$ and the $\mathrm{C}=\mathrm{C}$ stretching vibration, 


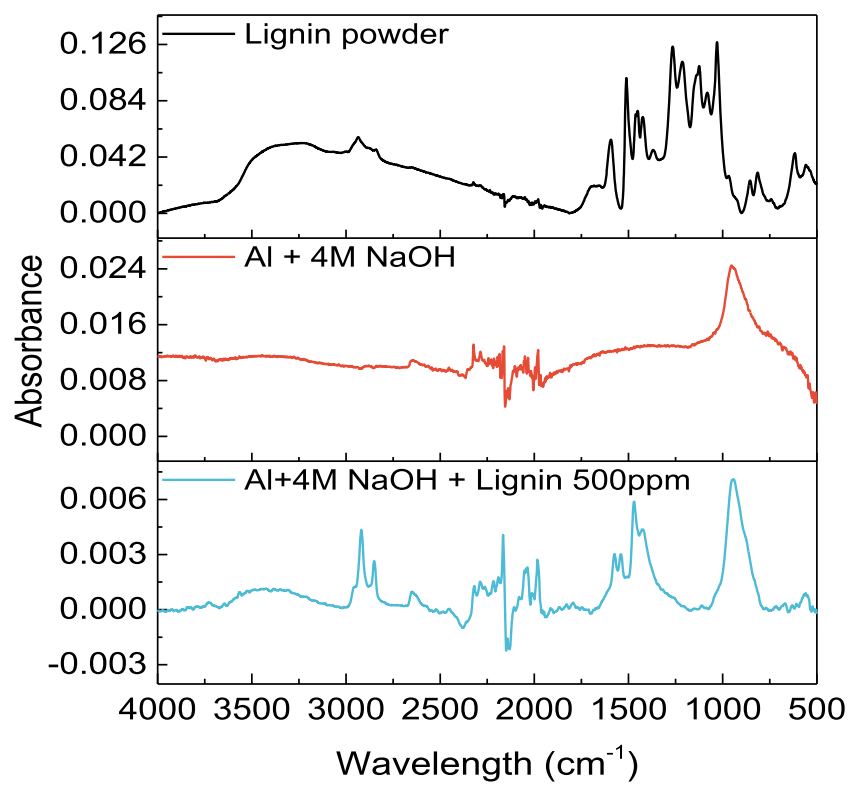

Figure 6. FT-IR spectra of the aluminum surface after $1 \mathrm{~h}$ of immersion in the presence and absence of lignin molecules and lignin powder.

remain the same. This indicates that the hydroxyl groups of lignin molecules interact with the aluminum surface.

Simulation Analysis on the Adsorption Behavior of Lignin in Al-Air Battery. To verify the most stable geometrical structure of lignin isomers, four types of lignin isomers are considered, as illustrated in Figure S4. The isomers have the orientations of hydroxyl groups $(-\mathrm{OH})$ and thiol groups $(-\mathrm{SH})$. The most stable isomers can be identified by the relative energy of $-4182.3 \mathrm{eV}$, which is isomer 1 , containing a single thiol group and two hydroxyl groups.

For isomer 1, Mulliken charge distributions of lignin molecules and the charge potential map are calculated, with the results illustrated in Figure 7a. The oxygen atoms of the hydroxyl (R-OH) group have the highest negative charge $(-0.710 \mathrm{au})$ and the hydrogen atoms of the hydroxyl (R-OH) group have the most positive charge $(0.540 \mathrm{au})$. The hydroxyl groups of the oxygen atoms simplify the adsorption as they are located in the outer parts of the lignin molecules. Moreover, $\mathrm{Al}$ atoms on the surface have a positive charge of 0.005 au and tend to undergo electrostatic interactions with other species with negative charges. Previous research has investigated the adsorption of heavy metal ions from aqueous solutions containing an additive, which has found out that the additive can be an adsorbent for heavy metal ions. Moreover, nonspecific adsorption of charged molecules has occurred because of the presence of hydroxyl groups in lignin molecules. $^{42,43}$ It is confirmed that three hydroxyl groups and one thiol group have negative charge values, as shown in Figure $7 \mathrm{a}, \mathrm{b}$. It is necessary to determine which functional group has the greatest influence on adsorption behavior. Therefore, the geometrical optimization for four different adsorption modes are examined, as shown in Figure S5, and the one shown in Figure $7 c$ is the most optimized structure for adsorption of lignin molecules. The adsorption energy is calculated with the following equation

$$
\Delta E_{\mathrm{ads}}=E_{\text {lignin } / \mathrm{Al}}-E_{\text {lignin }}-E_{\mathrm{Al}}
$$

where $E_{\text {lignin }}$ and $E_{\mathrm{Al}}$ are the energies of an isolated lignin molecule and a clean $\mathrm{Al}$ surface, respectively. $E_{\text {lignin/Al }}$ is the total energy of the lignin molecules adsorbed on the $\mathrm{Al}$ surface. A negative value of $\Delta E_{\text {ads }}$ indicates stable adsorption. ${ }^{44}$ The adsorption energy of the two equilibrium structures is -346.92 $\mathrm{kJ} \mathrm{mol}{ }^{-1}$, which represents chemisorption. This result is consistent with the FT-IR and Freundlich adsorption isotherm analyses. An ab initio molecular dynamics (AIMD) simulation is also performed to verify the optimized structure of chemisorption. The results of AIMD are shown in Figures $7 \mathrm{~d}$ and S6. The calculated adsorption energy from AIMD is $-349.3 \mathrm{~kJ} \mathrm{~mol}^{-1}$, indicating chemisorption. An exclusive

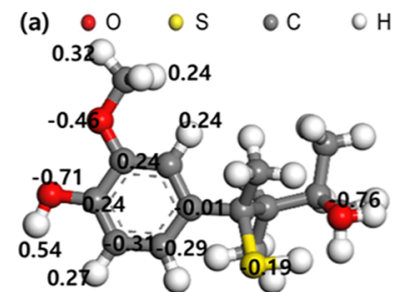

(b) Top view

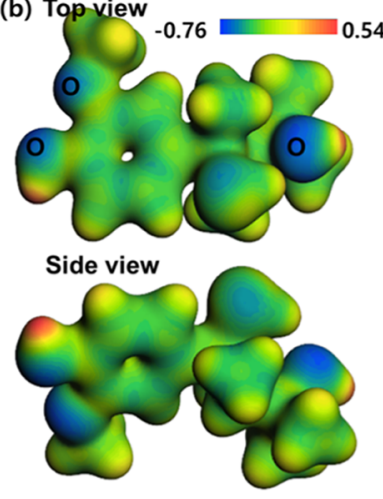

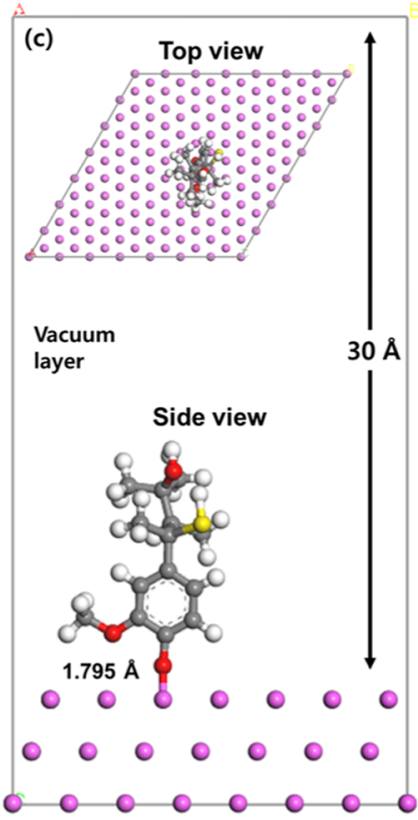

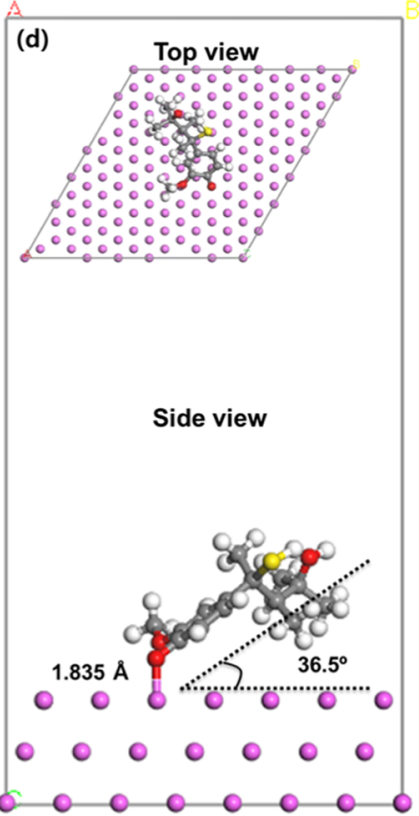

Figure 7. (a) Mulliken charge distributions of lignin molecules ranging from -0.770 to $0.300 \mathrm{au}$. (b) An electrostatic potential map for lignin molecules comparing the (c) initial and (d) final equilibrium structures (optimized equilibrium structure). 
geometrical structure is found by AIMD simulation and because the lignin molecule is leaning toward the aluminum surface, a moderate surface coverage can be achieved. As illustrated in Figure $7 \mathrm{c}$, the initial state shows an angle of $90^{\circ}$ between the lignin molecule and the aluminum surface. However, the angle between the lignin molecule and the aluminum surface is $36.5^{\circ}$. By comparing Figure $7 \mathrm{c}, \mathrm{d}$, an electrostatic repulsion of $-\mathrm{CH}_{3}$ atoms at the 7 o'clock position in Figure $7 \mathrm{c}$ can be attributed to the optimized adsorption structure with $36.5^{\circ}$. The distance between the lignin molecule and the aluminum surface increases by $0.04 \AA$, and it also has an optimized structure that minimized the repulsive force by making two hydrogens of $-\mathrm{CH}_{3}$ atoms level with the surface, as shown in Figure $7 \mathrm{~d}$. The results of the galvanostatic discharge test showing degradation of discharge efficiency at concentrations above $500 \mathrm{ppm}$ are correlated with the simulated geometrical structure with moderate surface coverage. Because the superior surface coverage due to the geometrical structure is made at a lower concentration, more residual lignin is likely to be produced at a higher concentration.

\section{CONCLUSIONS}

The addition of lignin molecules to a $4 \mathrm{M} \mathrm{NaOH}$ electrolyte has a positive effect on the performance of aluminum-air batteries. The corrosion inhibition efficiency for the $\mathrm{Al}$ anode in the alkaline solution is improved by the lignin molecules. Also, fuel efficiency is improved by $21.4 \%$, which is three times higher than that of a blank condition when lignin molecules are contained in the $4 \mathrm{M} \mathrm{NaOH}$ solution. The improved performance of the aluminum-air battery can be attributed to the chemisorption of lignin molecules on the aluminum surface, which is confirmed by Freundlich adsorption isotherm and SEM-EDS, LSM, and AFM analyses. In addition, the relationship between discharge efficiency and the concentration of lignin molecules can be explained by the effect of $R_{\mathrm{s}}$ values on electrolyte conductivity in EIS. The adsorption mechanism of lignin molecules is revealed by FT-IR analysis, which indicates chemisorption allowed for the formation of new bonds between the oxygen atoms in the hydroxyl groups of lignin molecules and the aluminum surface atoms, as well as quantum chemical calculations. The calculated adsorption energies and the density of transferred charges based on the density functional theory (DFT) method are consistent with FT-IR analysis, and the optimized geometrical structure exhibits moderate surface coverage, which explains the degradation in discharge efficiency above $500 \mathrm{ppm}$. Chemisorption of lignin molecules, therefore, has a positive effect on the corrosion inhibition of the aluminum anode due to the geometrical blockage of sites on the aluminum surfaces that can be attacked by the corrosion reaction. Moderate surface coverage due to chemisorption can also be attributed to the specific concentration that becomes the branch point of discharge efficiency.

\section{EXPERIMENTAL SECTION}

Materials. Aluminum anode with a purity of $99.99 \%$ was used in the aluminum-air batteries. A commercial gas diffusion electrode (GDE) composed of nickel mesh and a cobalt oxide catalyst (Meet Inc., Korea) was used as a cathode in a two-electrode cell, and graphite rods were used in a threeelectrode cell. Lignin was purchased from Sigma-Aldrich in
Korea. To prepare a $4 \mathrm{M} \mathrm{NaOH}$ solution, sodium hydroxide (Samchun Inc., Korea) was dissolved in deionized water. All reagents were of analytical grade.

Electrochemical Analysis. To conduct the weight-loss tests, aluminum slabs measuring $10 \mathrm{~mm} \times 10 \mathrm{~mm} \times 0.34 \mathrm{~mm}$ were prepared and cleaned with acetone, ethanol, and distilled water. After being weighed accurately by a sensitive balance, the specimens were immersed in $30 \mathrm{~mL}$ of the electrolytes in the presence and absence of lignin molecules at concentrations of $100,300,500,600,700,800,1000$, and $1500 \mathrm{ppm}$. All specimens were immersed for $1 \mathrm{~h}$, removed and rinsed with distilled water, dried, and accurately weighed again. The difference in mass before and after immersion yielded the weight loss. The average weight loss $(\Delta W)$ was obtained from triplicate experiments.

Galvanostatic discharge tests were conducted to evaluate the performance of aluminum-air batteries with electrolytes containing lignin. These tests were carried out at $20 \mathrm{~mA}$ $\mathrm{cm}^{-1}$ for $2 \mathrm{~h}$ in the presence and absence of lignin molecules with different concentrations in solution.

Potentiodynamic polarization tests were carried out to figure out the effect of the additive on the $\mathrm{Al}$ electrode. The tests were conducted by sweeping potentials at a scan rate of 0.166 $\mathrm{mV} \mathrm{s}^{-1}$. $^{45}$ Anodic polarization was measured by sweeping from the open-circuit potential (OCP) to a positive value of $0 \mathrm{~V}_{\mathrm{SCE}}$. Cathodic polarization was obtained by sweeping the potential from the OCP toward $-2.5 \mathrm{~V}_{\mathrm{SCE}}$.

Electrochemical impedance spectroscopy (EIS) was performed at the OCP in the absence and the presence of lignin molecules at concentrations from 100 to $1500 \mathrm{ppm}$ over a range of $100 \mathrm{kHz}$ to $100 \mathrm{mHz}$, with 10 points per decade and a sinusoidal wave perturbation of $10 \mathrm{mV}$ amplitude.

All electrochemical measurements were performed using a VSP-300 (Biologics) potentiostat. Also, electrochemical experiments were conducted using a self-designed cell assembly with an exposed area of $1 \mathrm{~cm}^{2}$.

The surface morphology of the aluminum surface immersed in a $4 \mathrm{M} \mathrm{NaOH}$ solution in the presence and absence of lignin molecules was examined using a JEOL JSM-7600F scanning electron microscope. The surfaces were randomly observed at different degrees of magnification. Energy-dispersive spectrometry (EDS) analysis was also performed after SEM morphological observation. Laser scanning microscopy (LSM) was performed using an OLYMPUS OLS5100 and atomic force microscopy (AFM) was performed using a JPK Nano Wizard Ultra Speed. Fourier-transform infrared spectra were recorded by a Nicolet IS50 FT-IR spectrophotometer. The spectral acquisition parameters were between 4000 and $400 \mathrm{~cm}^{-1}$, at 64 -times scanning, and a resolution of $4 \mathrm{~cm}^{-1}$.

Simulation Conditions. Simulation calculations were performed using Materials Studio (2019). The surface model, a slab model of $\mathrm{Al}$ with a (111) surface was cleaved with a top and thickness of $(0,3)$ and a vacuum thickness of 30 A. A supercell $(7 \times 7)$, large enough for a lignin molecule to be contained, was created so that precise interaction forces between the aluminum substrate and the lignin molecules could be obtained by minimizing the interaction forces among the lignin molecules. Geometry optimization was conducted using a CASTEP module with Perdew-Burke-Ernzerhof (PBE) functional DNP and a general gradient approximation (GGA) basis set. The convergence precision of the geometric optimization was set to fine for high accuracy in calculation, using specific parameters of $1.0 \times 10^{-5} \mathrm{eV}^{\text {atom }}{ }^{-1}$ for total 
energy, 0.001 A for maximum atomic displacement, $0.03 \mathrm{eV}$ $\mathrm{A}^{-1}$ for maximum atomic force, and $0.05 \mathrm{GPa}$ for maximum atomic stress. Based on convergence tests, the energy cutoff for the plane waves was $190.50 \mathrm{eV}$ for all models. The Brillouin zone $(4 \times 4 \times 4)$ was sampled by a Monkhorst-Pack $(\mathrm{MP}) k$ point mesh. The pseudopotentials were set as on-the-flygeneration (OTFG) ultrasoft. The self-consistent field (SFC) convergence was set to $1.0 \times 10^{-6} \mathrm{eV}$ atom $^{-1}$. The optimized lattice parameters of a designed supercell for the aluminum surface were $a, b=17.18 \AA$ and $c=30.00 \AA$, and the angle parameters were $\alpha, \beta=90^{\circ}$, and $\gamma=120^{\circ}$.

To determine the most stable geometrical isomer of lignin molecules, four types of isomers were considered and thermodynamic energies for four structures were calculated. ${ }^{24}$ Hydroxyl functional groups are contained in the molecular structure of lignin, and these functional groups can be the main adsorption site between lignin molecules and the aluminum surface. ${ }^{46}$ Based on the four adsorption mechanisms, adsorption of organic molecules at the anode/electrolyte interface may take place due to the electrostatic attraction force. ${ }^{47} \mathrm{We}$, therefore, analyzed the electronic charge distributions and electrostatic potential maps of the most stable adsorption structure to identify the possible atomic sites with the most positive and negative charges using a Mulliken population analysis function. Also, ab initio molecular dynamics (AIMD) was conducted to determine the equilibrium energy for adsorption of lignin molecules at $300 \mathrm{~K}$. The AIMD simulation was conducted for 0.3 ps with 1 fs time step in Nose-Hoover thermostat with NVT ensemble and random initial velocities.

\section{ASSOCIATED CONTENT}

\section{SI Supporting Information}

The Supporting Information is available free of charge at https://pubs.acs.org/doi/10.1021/acsomega.1c03533.

Representation of the lignin structure (Figure S1); laser scanning micrographs of the aluminum surface after immersion in the absence of lignin molecules (Figure S2); atomic force micrographs of the aluminum surface after immersion in the absence of lignin molecules (Figure S3); optimized structures and relative energies for four types of geometrical conformers for lignin molecules (Figure S4); geometrical optimization results for four different adsorption modes (Figure S5); total calculated energy variations $(\mathrm{eV})$ during $0.3 \mathrm{ps}$ of $\mathrm{ab}$ initio molecular dynamics (AIMD) simulation at $300 \mathrm{~K}$ (Figure S6) (PDF)

\section{AUTHOR INFORMATION}

\section{Corresponding Author}

Jung-Gu Kim - School of Advanced Materials Science and Engineering, College of Engineering, Sungkyunkwan University, Suwon-si, Gyeonggi-do 16419, Republic of Korea; Present Address: School of Advanced Materials Science and Engineering, Sungkyunkwan University, 2066, SeobuRo, Jangang-Gu, Suwon, Gyeonggi-Do 16419, Republic of Korea; Phone: +82 31290 7360; Email: kimjg@skku.ac.kr

\section{Authors}

Woo-hyuk Lee - School of Advanced Materials Science and Engineering, College of Engineering, Sungkyunkwan
University, Suwon-si, Gyeonggi-do 16419, Republic of

Korea; orcid.org/0000-0002-0112-3788

Seok-Ryul Choi - School of Advanced Materials Science and Engineering, College of Engineering, Sungkyunkwan University, Suwon-si, Gyeonggi-do 16419, Republic of Korea

Complete contact information is available at:

https://pubs.acs.org/10.1021/acsomega.1c03533

\section{Author Contributions}

The manuscript was written through contributions of all authors. All authors have given approval to the final version of the manuscript.

Notes

The authors declare no competing financial interest.

\section{ACKNOWLEDGMENTS}

This work was supported by the National Research Foundation of Korea (NRF) grant funded by the Korea Government (MEST) (no. NRF-2019R1A2B5B01070453).

\section{REFERENCES}

(1) Elia, G. A.; Kravchyk, K. V.; Kovalenko, M. V.; Chacón, J.; Holland, A.; Wills, R. G. A. An overview and prospective on $\mathrm{Al}$ and Al-ion battery technologies. J. Power Sources 2021, 481, No. 228870.

(2) Zhang, H.; Liu, X.; Li, H.; Hasa, I.; Passerini, S. Challenges and strategies for high-energy aqueous electrolyte rechargeable batteries. Angew. Chem., Int. Ed. 2021, 60, 598-616.

(3) Ryu, J.; Park, M.; Cho, J. Advanced Technologies for HighEnergy Aluminum-Air Batteries. Adv. Mater. 2019, 31, No. 1804784.

(4) Brandon, J.; Hopkins, Y. S.-H.; Hart, D. P. Suppressing corrosion in primary aluminum-air batteries via oil displacement. Adv. Mater. 2018, 362, 658-661.

(5) Schoetz, T.; Craig, B.; Ponce de Leon, C.; Bund, A.; Ueda, M.; Low, C. T. J. Aluminium-poly(3,4-ethylenedioxythiophene) rechargeable battery with ionic liquid electrolyte. J. Energy Storage 2020, 28, No. 101176.

(6) Yoo, D. J.; Choi, J. W. Elucidating the extraordinary rate and cycling performance of phenanthrenequinone in aluminum-complexion Batteries. J. Phys. Chem. Lett. 2020, 11, 2384-2392.

(7) Angell, M.; Zhu, G.; Lin, M. C.; Rong, Y.; Dai, H. Ionic liquid analogs of $\mathrm{AlCl}_{3}$ with urea derivatives as electrolytes for aluminum batteries. Adv. Funct. Mater. 2020, 30, No. 1901928.

(8) Liu, Y.; Sun, Q.; Li, W.; Adair, K. R.; Li, J.; Sun, X. A comprehensive review on recent progress in aluminum-air batteries. Green Energy Environ. 2017, 2, 246-277.

(9) Fan, L.; Lu, H.; Leng, J. Performance of fine structured aluminum anodes in neutral and alkaline electrolytes for $\mathrm{Al}$-air batteries. Electrochim. Acta 2015, 165, 22-28.

(10) Cho, Y.-J.; Park, I.-J.; Lee, H.-J.; Kim, J.-G. Aluminum anode for aluminum-air battery-Part I: Influence of aluminum purity. J. Power Sources 2015, 277, 370-378.

(11) Ren, J.; Ma, J.; Zhang, J.; Fu, C.; Sun, B. Electrochemical performance of pure $\mathrm{Al}, \mathrm{Al}-\mathrm{Sn}, \mathrm{Al}-\mathrm{Mg}$ and $\mathrm{Al}-\mathrm{Mg}-\mathrm{Sn}$ anodes for Al-air batteries. J. Alloys Compd. 2019, 808, No. 151708.

(12) Zhou, S.; Tian, C.; Alzoabi, S.; Xu, Y.; Jiao, Z.; Luo, K.; Peng, B.; Zhang, C.; Santos, N.; Cao, Y. Performance of an Al-0.08Sn$0.08 \mathrm{Ga}-\mathrm{xMg}$ alloy as an anode for $\mathrm{Al}-$ air batteries in alkaline electrolytes. J. Mater. Sci. 2020, 55, 11477-11488.

(13) Park, I.-J.; Choi, S.-R.; Kim, J.-G. Aluminum anode for aluminum-air battery - Part II: Influence of In addition on the electrochemical characteristics of $\mathrm{Al}-\mathrm{Zn}$ alloy in alkaline solution. $J$. Power Sources 2017, 357, 47-55.

(14) Lee, W.-H.; Choi, S.-R.; Kim, J.-G. Effect of agar as electrolyte additive on the aluminum-air batteries. J. Electrochem. Soc. 2020, 167, No. 110503. 
(15) Jiang, H.; Yu, S.; Li, W.; Yang, Y.; Yang, L.; Zhang, Z. Inhibition effect and mechanism of inorganic-organic hybrid additives on threedimension porous aluminum foam in alkaline Al-air battery. J. Power Sources 2020, 448, No. 227460.

(16) Wu, S.; Zhang, Q.; Sun, D.; Luan, J.; Shi, H.; Hu, S.; Tang, Y.; Wang, H. Understanding the synergistic effect of alkyl polyglucoside and potassium stannate as advanced hybrid corrosion inhibitor for alkaline aluminum-air battery. Chem. Eng. J. 2020, 383, No. 123162.

(17) Teabnamang, P.; Kao-ian, W.; Nguyen, M. T.; Yonezawa, T.; Cheacharoen, R.; Kheawhom, S. High-capacity dual-electrolyte aluminum-air battery with circulating methanol anolyte. Energies 2020, 13, No. 2275.

(18) Sun, Z.; Lu, H. Performance of Al-0.5In as anode for Al-air battery in inhibited alkaline solutions. J. Electrochem. Soc. 2015, 162, A1617-A1623.

(19) Pino, M.; Chacón, J.; Fatás, E.; Ocón, P. Performance of commercial aluminium alloys as anodes in gelled electrolyte aluminium-air batteries. J. Power Sources 2015, 299, 195-201.

(20) Liang, R.; Su, Y.; Sui, X.-L.; Gu, D.-M.; Huang, G.-S.; Wang, Z.B. Effect of $\mathrm{Mg}$ content on discharge behavior of $\mathrm{Al}-0.05 \mathrm{Ga}-0.05 \mathrm{Sn}$ $0.05 \mathrm{~Pb}-\mathrm{xMg}$ alloy anode for aluminum-air battery. J. Solid State Electrochem. 2019, 23, 53-62.

(21) Deyab, M. A. Effect of nonionic surfactant as an electrolyte additive on the performance of aluminum-air battery. J. Power Sources 2019, 412, 520-526.

(22) Moghadam, Z.; Shabani-Nooshabadi, M.; Behpour, M. Electrochemical performance of aluminium alloy in strong alkaline media by urea and thiourea as inhibitor for aluminium-air batteries. $J$. Mol. Liq. 2017, 242, 971-978.

(23) Dattatraya Saratale, G.; Bhosale, R.; Shobana, S.; Banu, J. R.; Pugazhendhi, A.; Mahmoud, E.; Sirohi, R.; Kant Bhatia, S.; Atabani, A. E.; Mulone, V.; Yoon, J. J.; Seung Shin, H.; Kumar, G. A review on valorization of spent coffee grounds (SCG) towards biopolymers and biocatalysts production. Bioresour. Technol. 2020, No. 123800.

(24) Sharma, S.; Sharma, A.; Mulla, S. I.; Pant, D.; Sharma, T.; Kumar, A. Lignin as Potent Industrial Biopolymer: An Introduction. In Lignin; Sharma, S.; Kumar, A., Eds.; Springer Nature: Switzerland, 2020; pp 1-15.

(25) Espinoza-Acosta, J. L.; Torres-Chávez, P. I.; Olmedo-Martínez, J. L.; Vega-Rios, A.; Flores-Gallardo, S.; Zaragoza-Contreras, E. A. Lignin in storage and renewable energy applications: A review. J. Energy Chem. 2018, 27, 1422-1438.

(26) Shrestha, L.; Thapa, M.; Shrestha, R.; Maji, S.; Pradhananga, R.; Ariga, K. Rice husk-derived high surface area nanoporous carbon materials with excellent iodine and methylene blue adsorption properties. C 2019, 5, No. 10.

(27) Tolesa, L. D.; Gupta, B. S.; Lee, M. J. Treatment of coffee husk with ammonium-based ionic liquids: lignin extraction, degradation, and characterization. ACS Omega 2018, 3, 10866-10876.

(28) Monticelli, C.; Balbo, A.; Esvan, J.; Chiavari, C.; Martini, C.; Zanotto, F.; Marvelli, L.; Robbiola, L. Evaluation of 2-(salicylideneimino) thiophenol and other schiff bases as bronze corrosion inhibitors by electrochemical techniques and surface analysis. Corros. Sci. 2019, 148, 144-158.

(29) Sun, Z.; Yang, J.; Qi, Y.; Wang, F.; Hong, W.; Li, H.; Jiang, Y. Facile preparation of hydroxyl-rich mesoporous magnesium silicate with excellent adsorption performance. Surf. Interfaces 2020, 20, No. 100519.

(30) Guo, L.; Tan, J.; Kaya, S.; Leng, S.; Li, Q.; Zhang, F. Multidimensional insights into the corrosion inhibition of 3,3dithiodipropionic acid on Q235 steel in $\mathrm{H}_{2} \mathrm{SO}_{4}$ medium: A combined experimental and in silico investigation. J. Colloid Interface Sci. 2020, $570,116-124$.

(31) Tawfik, S. M.; Negm, N. A. Vanillin-derived non-ionic surfactants as green corrosion inhibitors for carbon steel in acidic environments. Res. Chem. Intermed. 2016, 42, 3579-3607.

(32) Soliman, H. N. Influence of 8-hydroxyquinoline addition on the corrosion behavior of commercial $\mathrm{Al}$ and $\mathrm{Al}-\mathrm{HO} 411$ alloys in $\mathrm{NaOH}$ aqueous media. Corros. Sci. 2011, 53, 2994-3006.
(33) Deyab, M.; Essehli, R.; El Bali, B. Inhibition of copper corrosion in cooling seawater under flowing conditions by novel pyrophosphate. RSC Adv. 2015, 5, 64326-64334.

(34) Aourabi, S.; Driouch, M.; Sfaira, M.; Mahjoubi, F.; Hammouti, B.; Verma, C.; Ebenso, E. E.; Guo, L. Phenolic fraction of Ammi visnaga extract as environmentally friendly antioxidant and corrosion inhibitor for mild steel in acidic medium. J. Mol. Liq. 2021, 323, No. 114950.

(35) Mishra, P. K.; Ekielski, A. The self-assembly of lignin and its application in nanoparticle synthesis: a short review. Nanomaterials 2019, 9, No. 243.

(36) Guerra, A.; Gaspar, A. R.; Contreras, S.; Lucia, L. A.; Crestini, C.; Argyropoulos, D. S. On the propensity of lignin to associate: a size exclusion chromatography study with lignin derivatives isolated from different plant species. Phytochemistry 2007, 68, 2570-2583.

(37) Fila, D.; Hubicki, Z.; Kołodyńska, D. Recovery of metals from waste nickel-metal hydride batteries using multifunctional Diphonix resin. Adsorption 2019, 25, 367-382.

(38) Wei, W.; Liu, Z.; Liang, C.; Han, G.-C.; Han, J.; Zhang, S. Synthesis, characterization and corrosion inhibition behavior of 2aminofluorene bis-Schiff bases in circulating cooling water. RSC Adv. 2020, 10, 17816-17828.

(39) Thanapackiam, P.; Rameshkumar, S.; Subramanian, S. S.; Mallaiya, K. Electrochemical evaluation of inhibition efficiency of ciprofloxacin on the corrosion of copper in acid media. Mater. Chem. Phys. 2016, 174, 129-137.

(40) Levy, N.; Lori, O.; Gonen, S.; Mizrahi, M.; Ruthstein, S.; Elbaz, $\mathrm{L}$. The relationship of morphology and catalytic activity: A case study of iron corrole incorporated in high surface area carbon supports. Carbon 2020, 158, 238-243.

(41) Mohan, V.; Naske, C. D.; Britten, C. N.; Karimi, L.; Walters, K. B. Hydroxide-catalyzed cleavage of selective ester bonds in phosphatidylcholine: An FTIR study. Vib. Spectrosc. 2020, 109, No. 103055.

(42) Zhang, K.; Yang, W.; Ge, F.; Xu, B.; Chen, Y.; Yin, X.; Liu, Y.; Zuo, H. A self-curing konjac glucomannan $/ \mathrm{CaCO} 3$ coating for corrosion protection of AA5052 aluminum alloy in $\mathrm{NaCl}$ solution. Int. J. Biol. Macromol. 2020, 151, 691-701.

(43) Zhang, K.; Yang, W.; Yin, X.; Chen, Y.; Liu, Y.; Le, J.; Xu, B. Amino acids modified konjac glucomannan as green corrosion inhibitors for mild steel in $\mathrm{HCl}$ solution. Carbohydr. Polym. 2018, 181, 191-199.

(44) Zhang, J.; Li, T.; Li, X.; Liu, Y.; Li, N.; Wang, Y.; Li, X. A key role of inner-cation-pi interaction in adsorption of $\mathrm{Pb}$ (II) on carbon nanotubes: Experimental and DFT studies. J. Hazard. Mater. 2021, 412, No. 125187.

(45) ASTM G 5-94: Standard Reference Test Method For Making Potentiostatic and Potentiodynamic Anodic Polarization Measurements. Annual Book of ASTM Standards; ASTM International, 2004; Vol. 3, pp 48-58.

(46) Yin, C.; Kong, M.; Zhang, J.; Wang, Y.; Ma, Q.; Chen, Q.; Liu, $\mathrm{H}$. Influence of hydroxyl groups on the inhibitive corrosion of gemini surfactant for carbon steel. ACS Omega 2020, 5, 2620-2629.

(47) Abdel Hameed, R. S.; Al-Bagawi, A. H.; Shehata, H. A.; Shamroukh, A. H.; Abdallah, M. Corrosion inhibition and adsorption properties of some heterocyclic derivatives on C-Steel surface in $\mathrm{HCl}$. J. Bio- Tribo-Corros. 2020, 6, No. 51. 